Revista Jurídica del Departamento de Derecho

Academia de Derecho Administrativo

Tercera Época Año2. No. 5. Vol. 1/ Julio-Diciembre 2011.

\title{
¿"Las políticas de seguridad pública, en etapa permanente de debate"? Estudio de Caso México
}

\author{
Adria Velia González Beltrones, \\ Guadalupe Aleida Valenzuela Miranda \\ Alipia Avendaño Enciso \\ María Victoria Olivarreta Carmona \\ Jesús Miguel Maya Rodríguez
}

Resumen

Al Contrastar no solo los conceptos sino la percepción de autoridades y gobernados en relación a la seguridad pública con lo que los expertos denominan etapas de la formulación de políticas públicas se extraen las propuestas de las autoridades y de los gobernados que implican nuevas acciones o nuevos mecanismos que requieren para su implementación en algunos casos :el respaldo dentro del orden jurídico para salvaguardar el estado de derecho y en otros casos un previo e intenso debate en distintos foros al respecto.

Palabras Clave. Políticas públicas, seguridad pública, estado de derecho

Abstract

By comparing not only the concepts but also the perception of authorities and that of the people governed by them in relation to public safety with what experts call stages of the formulation of public policies, proposals of the authorities and the governed people are extracted that involve new shares or new mechanisms required for its implementation in some cases: the backing within the legal order to safeguard the rule of law and in other cases also a prior and intense debate in various forums on the subject.

Key words. Public policy, public security, rule of law

\section{Introducción}

Corre el año 2011 y nuestro país flota en un ambiente contradictorio de "seguridad pública”: el oficial, el que describen los medios de comunicación y el que vive el ciudadano día a día. En un año de transición en México, puesto que está en puerta el inicio formal de la contienda por la sucesión presidencial para el sexenio 2012-2018; las notas distintivas no podrían ser mas desoladoras: un Presidente de la República inmerso en una "guerra" o "lucha" asimétrica contra el "narcotráfico" que ha originado una escalada de violencia inadmisible recaudando hasta este mes de octubre una pérdida de más de 50,000 vidas con el desprestigio histórico e irreparable de las instituciones y los funcionarios que al frente de ellas juraron velar por la obtención del bienestar del pueblo mexicano y que en contrapartida solo han propiciado: 1) al “ejército en la calle” ; 2)una economía nacional artificialmente sostenida para resistir el fin de sexenio. 3) escalada de precios,4)pérdida del poder adquisitivo por salarios asimétricos al trabajo que pretenden remunerar,5) desempleo infinitesimal, 6)cuestionada calidad en la educación y un largo etcétera que nos cede el espacio para el tratamiento del tema que ha motivado nuestra presencia en la 
celebración de este Primer Seminario. Dada la importancia de las Políticas Públicas para la transformación social, se hace necesario indagar por qué y bajo qué circunstancias las de Seguridad Pública, constituyen un factor decisivo para promover o inhibir la deseada evolución social. Por cuestión de orden señalamos primeramente que usualmente el vocablo Políticas Públicas (PP) se refiere a los programas que un gobierno, cualquiera que sea, desarrolla en función de un problema o situación determinada

Expertos como William Jenkins afirman que una política pública en su sentido de policy es "un conjunto de decisiones interrelacionadas tomadas por un actor o grupo de actores políticos preocupados por elegir metas y medios para alcanzarlas en una situación determinada, $\mathrm{y}$ en donde, en principio, los actores tienen el poder de alcanzar dichas metas" 11

Acorde a Aguilar Villanueva "una política es un comportamiento propositivo, intencional, planeado, no simplemente reactivo, casual. Se pone en movimiento con la decisión de alcanzar ciertos objetivos a través de ciertos medios: es una acción con sentido. Es un proceso, un curso de acción que involucra todo un conjunto complejo de decisiones y operadores $^{12 \mathrm{i}}$. La política también es una actividad de comunicación pública.

Por su parte en relación al ámbito público, el propio Luis F Aguilar Villanueva llama así "al campo de interacciones, interpelaciones ,e interpretaciones en que los ciudadanos individuales, por sí mismos o por los voceros de sus organizaciones hacen políticas y políticas, y concierne a lo que es accesible y disponible sin excepción para todos los individuos de la asociación política"13 en este sentido "las PP no se refieren únicamente a las acciones de los gobiernos perse, es decir de las acciones que emanan de su criterio de la racionalidad que se deriva de ser depositario de la soberanía del estado por parte del pueblo, sino también a las acciones derivadas de una racionalidad social, entendida como aquélla que surge de la elección de medios para satisfacer metas dentro del contexto de las necesidades de la sociedad. El estudio de las PP se refiere a entender y sugerir, dentro de un enfoque multidisciplinario, líneas de acción de gobierno a partir de un proceso de toma de decisiones interrelacionado, y no surgido exclusivamente de un centro decisional único generalmente ubicado en la figura del gobierno"14

De otra parte, Dye afirma que la PP para su formulación, aplicación, gestión y evaluación necesita de los elementos arte y laboriosidad. Arte porque demanda creatividad, imaginación en la identificación y descripción de los problemas sociales, y laboriosidad porque necesita de un profundo conocimiento de política, economía, derecho, administración, sociología y estadística.la combinación de creatividad con conocimientos facilitará la elaboración de una PP que se traducirá en la composición de modelos.

\section{Justificación}

\footnotetext{
${ }^{11}$ Jenkins, Williams, Policy Analisisa political and organization perspective,Inglaterra,Mortin Robertson and Company,1978,p.15

${ }^{12}$ AguilarVillanueva Luis, Estudio Introductorio a las Políticas Públicas

${ }^{13}$ Agilar Villanueva, Luis,Colección de antologías de políticas públicas, México Miguel Angel Porrúa,1992,p.28

${ }^{14}$ Buen día Alejandro,"Políticas públicas,enfoques y prospectivas", Revista del Instituto de Administración Pública del Estado de Mëxico.(IAPEM),México,julio-agosto,1997,p.14 
Revista Jurídica del Departamento de Derecho Academia de Derecho Administrativo

Tercera Época Año2. No. 5. Vol. 1/ Julio-Diciembre 2011.

Después de la Segunda Guerra Mundial fue espontáneo y lógico llamar “análisis de políticas”, a la actividad de mejorar las decisiones de política mediante la incorporación sistemática de teoría y método científico. Logrando así una nueva forma de ver y estudiar las políticas. ${ }^{15}$

Por otra parte, señalan los expertos que si el diseño de una estrategia no es tarea de una sola persona u organización, tampoco se trata de una política que pueda promoverse en forma tecnocrática, por un grupo de expertos o instituciones especializadas, es decir, tienen que ser un conjunto de actores los cuales interactúen y negocien, obteniendo así una Política Pública que logre beneficios convergentes a todos los involucrados. ${ }^{16}$

Ahora bien en relación con la seguridad pública y los antecedentes de la política pública nacional al respecto, tenemos que, a partir de 1945 y después de dos guerras mundiales, los derechos humanos, y por extensión la seguridad pública, se convierten, oficialmente, en requisitos de legitimidad y justicia de las instituciones modernas. En este sentido, en la relación derechos humanos-seguridad pública, es fácil distinguir a la seguridad pública como medio y a los derechos humanos como fin. Hoy en día la seguridad pública se legitima como un derecho fundamental

La seguridad pública es, como explica Sergio García Ramírez, una cualidad de los espacios públicos y privados, que se caracteriza por la inexistencia de amenazas que socaven o supriman los bienes y derechos de las personas y en la que existen condiciones propicias para la convivencia pacífica y el desarrollo individual y colectivo de la sociedad. La construcción de esta cualidad implica la participación de múltiples recursos de la sociedad y del Estado. Las definiciones y estrategias del actual gobierno federal (como ocurre en prácticamente todo el mundo) se distinguen por actuar sólo en el ámbito penal."17 Echando una mirada al encuadre o

\section{Marco legal}

En nuestro país el Artículo 21 de la Constitución Política de los Estados Unidos Mexicanos establece que la seguridad pública es una función a cargo de la Federación, los Estados, el Distrito Federal y los Municipios. A su vez el Plan Nacional de Desarrollo 2007-2012, establece como uno de los objetivos de su eje rector"Estado de Derecho y Seguridad" la premisa fundamental de la interacción social, conforme a la cual las personas necesitan garantías de seguridad para su Desarrollo Humano Sustentable, con la finalidad de que puedan actuar y desarrollarse en forma libre y segura; el propio Plan Nacional de Desarrollo 2007-2012 prevé que la seguridad pública y el Estado de Derecho forman un binomio esencial para hacer realidad el Desarrollo Humano Sustentable, en la cual la propia ciudadanía es la que proporciona información clave sobre la manifestación pública

\footnotetext{
${ }^{15}$ Los expertos afirman que los tres componentes principales de cualquier política son: los principios que la orientan (la ideología o argumentos que la sustentan); los instrumentos mediante los cuales se ejecuta (incluyendo aspectos de regulación, de financiamiento, y de mecanismos de prestación de las políticas) y los servicios o acciones principales que se llevan o deberían llevarse a cabo de acuerdo a los principios propuestos.

${ }^{16}$ López Ruiz Domingo 'Cadénas Ayala Carlos Eduardo, ¿Qué Es Una Política Pública? http://www.unla.edu.mx

${ }^{17}$ http://www.diputados.gob.mx
} 
del fenómeno delictivo, por lo que dicho instrumento propone integrar la participación de la ciudadanía al sistema de seguridad. Asimismo, el Artículo 30 bis de la Ley Orgánica de la Administración Pública Federal, señala que la Secretaría de Seguridad Pública (SSP) tendrá a su cargo salvaguardar la integridad y el patrimonio de las personas, prevenir la comisión de delitos y preservar la libertad, el orden y la paz públicos. El artículo 8 fracción II de la Ley Federal de Responsabilidades Administrativas de los Servidores Públicos, establece la obligación de formular y ejecutar planes y programas. La SSP, en el marco del Sistema Nacional de Planeación Democrática (SNPD), con fundamento en los artículos 26 apartado A constitucional, y 16, fracción IV, 21, 22, 26, 29, 32 y 37 de la Ley de Planeación, es responsable de elaborar el Programa Nacional de Seguridad Pública 20082012. (PNSP) ${ }^{18}$; que es el punto de convergencia de las distintas políticas públicas, programas y acciones de las diversas instituciones y organizaciones gubernamentales responsables de la seguridad en el país. De otra parte, dado que una perspectiva global e integral del fenómeno delictivo es indispensable para diseñar e instrumentar acciones que permitan prevenir y, en su caso, contrarrestar tanto sus impactos como la extensión y vigencia de sus efectos adversos conviene contextualizarlo a grosso modo.

\section{México en Latinoamérica}

Primeramente cabe reconocer que la criminalidad es un problema global, compartido que la ubica entre los principales retos y desafíos en el mundo, a la par de la corrupción, el tráfico de drogas, la propagación de enfermedades infecciosas y el cambio climático. Su alcance trasnacional es fortalecido por su elevada capacidad y velocidad para ajustarse y aprovechar las rendijas de la globalización.

En el contexto internacional, de acuerdo con la encuesta Global Opinion Trends 20022007, realizada en 47 países, México ocupa el lugar 17 entre los países donde la delincuencia es considerada como problema muy grave.

Prácticamente en toda América Latina la criminalidad se percibe como problema muy grave. Esto es más evidente en Chile, Brasil y Perú. En México y Bolivia tal opinión es compartida casi por dos tercios de la ciudadanía. ${ }^{19}$ Ahora bien si en términos del precepto 21 Constitucional "Las instituciones de seguridad pública se rigen por los principios de: legalidad, objetividad, eficiencia, profesionalismo, honradez y respeto a los derechos

\footnotetext{
${ }^{18}$ Las propuestas de contenido para la integración del PNSP se formularon de acuerdo con lo dispuesto en los Artículos 3 y 17, fracción I de la Ley General que Establece las Bases de Coordinación del Sistema Nacional de Seguridad Pública (LGEBC-SNSP), y con lo que establecen los artículos 9 y 15, fracción III del mismo ordenamiento. En el proceso de integración del $\mathrm{PNSP}^{18}$ se incluyeron tanto las consideraciones de los integrantes del Consejo Nacional de Seguridad Pública (CNSP), como de la ciudadanía.

EI PNSP concreta y expresa las inquietudes y demandas de gobierno y sociedad para el establecimiento e instrumentación de políticas y acciones integrales e intersectoriales en materia de seguridad pública.
}

${ }^{19}$ En México, la delincuencia e inseguridad se ubican entre los principales problemas del país y en ocasiones llegan a disputar el primer sitio a los problemas económicos, como sucedió en 2005 y 2006.

Según datos de la firma Consulta Mitofsky, actualmente delincuencia e inseguridad se ubican en segundo sitio como principal problema del país (17.7\%), detrás de los problemas económicos (31.1\%) con un considerable margen de diferencia entre unos y otros 2. 
humanos". En contrapartida, para el ciudadano común el tema de mayor interés -fuera de los discursos oficiales- es el de la

\section{Planteamiento del problema}

La falta de seguridad. ¿Qué tipo de seguridad es la que demanda el ciudadano mexicano y cuál es el tipo de seguridad que ofrecen los gobiernos en turno?

A partir de unos años a la fecha, el uso de la voz seguridad pública ha comenzado a familiarizarse entre los habitantes del país, porque el fenómeno de la inseguridad, desafortunadamente se ha generalizado a lo largo y ancho de su territorio, de manera terrorífica y cotidiana, de forma tal que poco a poco se pierde no solo la capacidad de asombro sino la de indignación. Si bien la expresión “derechos humanos” alcanzó su auge en la década de los noventas, a propósito del neoliberalismo, en este inicio del presente siglo, el tema de la seguridad pública en México se ha vuelto recurrente: se publicó una ley con ese mismo nombre; a nivel federal, la Secretaría de Seguridad Pública elaboró como instrumento normativo y de planeación, el Programa Nacional de Seguridad Pública ${ }^{20}$ el cual por lo menos en el papel da prioridad a "la prevención de conductas delictivas con mecanismos que garanticen la convivencia social y familiar segura en lugares públicos y en el entorno escolar, así como fortalecer la cultura de la legalidad y la atención a víctimas del delito. ${ }^{21}$

Igualmente, el decreto por el que se aprueba el programa indica que éste será de observancia obligatoria para las dependencias y entidades de la Administración Pública Federal, que deben coordinarse con los gobiernos estatales y de los municipios para su ejecución, en el marco del Sistema Nacional de Seguridad Pública... De igual forma se elaboró el Programa Sectorial de Seguridad Pública 2007-2012, problemática en materia de seguridad pública, cuyos dos pilares en los que se apoya, son el combatir la delincuencia y corregir las conductas sociales que propician la comisión de delitos. Con lo anterior se propone restablecer el sentido original de la seguridad pública, "proteger a las personas en su integridad física, bienes y derechos y servir a la sociedad resguardando las libertades y el orden públicos”

No obstante tan buenos propósitos, plasmados en los precitados ordenamientos y documentos nacionales y a pesar de los esfuerzos así direccionados, los ciudadanos continuamos con la intranquilidad y en ciertos casos con aprensión extrema de:caminar por las calles, de asistir a un lugar público, comercial, de esparcimiento o

\footnotetext{
${ }^{20}$ El Programa Nacional de Seguridad Pública, contiene los principios generales de gobierno y los criterios básicos de la acción gubernamental, que perfilan el nuevo modelo del sistema de seguridad pública nacional. Parte de un análisis sobre los factores que interactúan en la seguridad pública, estudiando sus causas y efectos, así como los retos que enfrentan las corporaciones policiales integrantes del Sistema Nacional de Seguridad Pública, en materia de personal, equipamiento, infraestructura inmobiliaria, comunicaciones y tecnología.

${ }^{21}$ Otra finalidad es fomentar número uno es el respeto y protección a los derechos humanos de la población por los encargados de la seguridad pública en los tres órdenes de gobierno. Además combatir frontalmente el delito y consolidar el Estado de derecho con la coordinación de los tres niveles de gobierno, a través de la Estrategia Nacional de Prevención del Delito y Combate a la Delincuencia en el marco del Sistema Nacional de Seguridad Pública.
}

Asimismo, se "prevé también recuperar el sentido original del sistema penitenciario, para que en los centros de reclusión se garantice el cumplimiento de las sanciones impuestas a los internos con estricto apego a la ley y procurar la creación de condiciones propicias para la reinserción social." 
eclesiástico, de transitar de día o de noche por las otroras rúas urbanas y tranquilas carreteras nacionales, locales o municipales, de abordar un taxi o de acercarse a/o que se un policía. En este contexto nuestro

Objetivo es examinar si las Políticas Públicas del PND 2007-.2012 tendientes a consolidar una nueva política de Estado de Seguridad Pública han dado resultados. A la luz de la siguiente

Hipótesis "el tema de las PP en materia de Seguridad Pública está en permanente proceso de discusión.”

Metodología Contrastar no solo los conceptos sino la percepción de autoridades y gobernados en relación a la seguridad pública con lo que los expertos denominan etapas de la formulación de políticas públicas para extraer conclusiones.

.Para ello en la siguiente tabla se enumera y examina ${ }^{22}$ algunas de las medidas contra la inseguridad propuestas desde el inicio de la administración del presidente Felipe Calderón por los Poderes de la Unión en unos casos y en otros por la la sociedad civil.

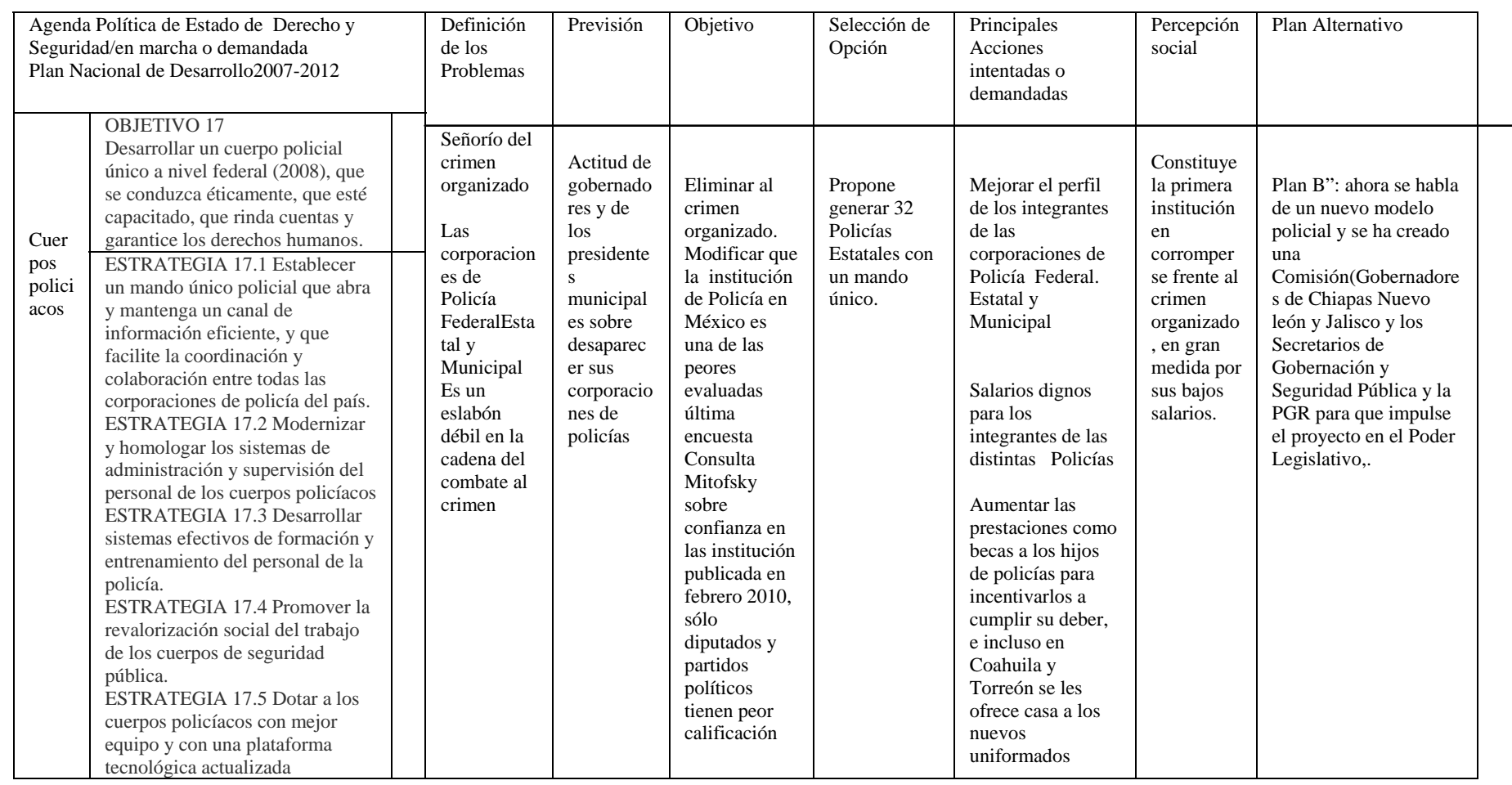

\footnotetext{
${ }^{22}$ Ver Formulación de las políticas Pública en ¿Qué es una Política Pública? Ruiz López Domingo Cadénas Ayala Carlos Eduardo http://www.unla.edu.mx
} 


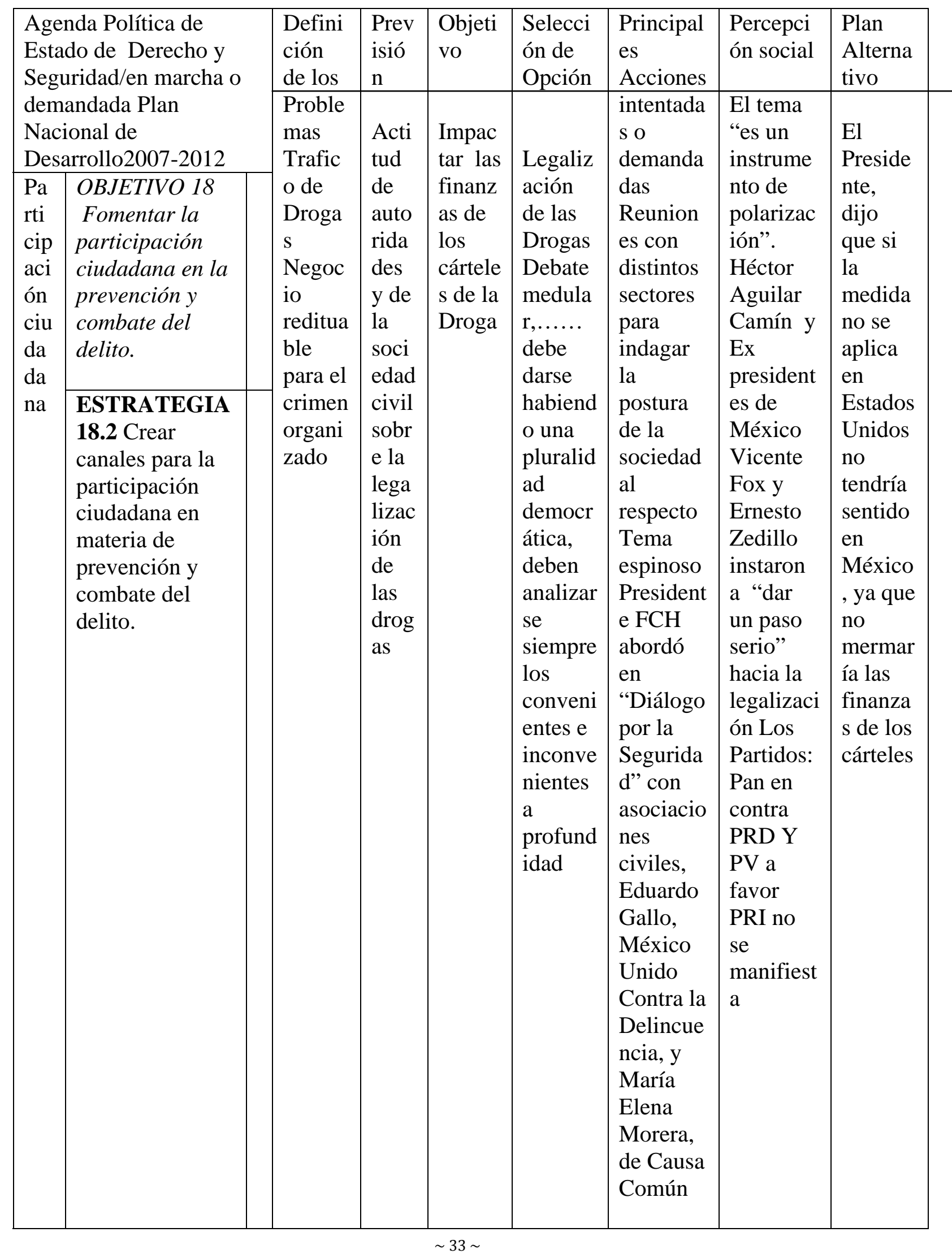


Revista Jurídica del Departamento de Derecho

Academia de Derecho Administrativo

\begin{tabular}{|c|c|c|c|c|c|c|c|c|}
\hline \multicolumn{2}{|c|}{$\begin{array}{l}\text { Agenda Política de } \\
\text { Estado de Derecho y } \\
\text { Seguridad/en marcha o } \\
\text { demandada Plan } \\
\text { Nacional de } \\
\text { Desarrollo2007-2012 }\end{array}$} & $\begin{array}{l}\text { Defini } \\
\text { ción } \\
\text { de los } \\
\text { Proble } \\
\text { mas }\end{array}$ & $\begin{array}{l}\text { Previs } \\
\text { ión }\end{array}$ & $\begin{array}{l}\text { Obje } \\
\text { tivo }\end{array}$ & $\begin{array}{l}\text { Selecci } \\
\text { ón de } \\
\text { Opción }\end{array}$ & $\begin{array}{l}\text { Principales } \\
\text { Acciones } \\
\text { intentadas o } \\
\text { demandada } \\
\text { s }\end{array}$ & $\begin{array}{l}\text { Perce } \\
\text { pción } \\
\text { social }\end{array}$ & $\begin{array}{l}\text { Plan } \\
\text { Alternativo }\end{array}$ \\
\hline $\begin{array}{l}\text { De } \\
\text { rec } \\
\text { ho } \\
\text { s } \\
\text { hu } \\
\text { ma } \\
\text { no } \\
\text { s }\end{array}$ & $\begin{array}{l}\text { OBJETIVO } 8 \\
\text { Recuperar la } \\
\text { fortaleza del } \\
\text { Estado y la } \\
\text { seguridad en la } \\
\text { convivencia } \\
\text { social mediante } \\
\text { el combate } \\
\text { frontal y eficaz } \\
\text { al narcotráfico y } \\
\text { otras } \\
\text { expresiones del } \\
\text { crimen } \\
\text { organizado. } \\
\text { ESTRATEGIA } \\
\text { 8.3 Alcanzar y } \\
\text { consolidar } \\
\text { estándares } \\
\text { internacionales } \\
\text { en materia de } \\
\text { prevención y } \\
\text { combate al } \\
\text { lavado de dinero } \\
\text { de procedencia } \\
\text { ilícita. } \\
\text { ESTRATEGIA } \\
\text { 8.4 } \\
\text { Desarticulación } \\
\text { de cadenas } \\
\text { delictivas } \\
\text { mediante la } \\
\text { destrucción de } \\
\text { los nodos de } \\
\text { creación de } \\
\text { valor. }\end{array}$ & $\begin{array}{l}\text { Recurs } \\
\text { os de } \\
\text { proced } \\
\text { encia } \\
\text { ilícita } \\
\text { (lavad } \\
\text { o de } \\
\text { dinero } \\
\text { ). }\end{array}$ & $\begin{array}{l}\text { Actitu } \\
\text { d de } \\
\text { socie } \\
\text { dad } \\
\text { civil } \\
\text { en } \\
\text { relaci } \\
\text { ón a } \\
\text { la } \\
\text { legisl } \\
\text { ación } \\
\text { respe } \\
\text { ctiva. }\end{array}$ & $\begin{array}{l}\text { Impa } \\
\text { ctar } \\
\text { las } \\
\text { finan } \\
\text { zas } \\
\text { de } \\
\text { los } \\
\text { cárte } \\
\text { les } \\
\text { de la } \\
\text { Drog } \\
\text { a }\end{array}$ & $\begin{array}{l}\text { Legisla } \\
\text { ción } \\
\text { sobre la } \\
\text { extinci } \\
\text { ón de } \\
\text { domini } \\
\text { o y } \\
\text { regulari } \\
\text { zacione } \\
\text { s } \\
\text { bancari } \\
\text { as }\end{array}$ & $\begin{array}{l}\text { Investigar } \\
\text { recursos } \\
\text { de } \\
\text { procedenci } \\
\text { a ilícita } \\
\text { El único } \\
\text { juicio } \\
\text { proviene } \\
\text { de una } \\
\text { finca de la } \\
\text { Ciudad de } \\
\text { México } \\
\text { utilizada } \\
\text { por el } \\
\text { crimen } \\
\text { organizad } \\
\text { o pasó a } \\
\text { manos del } \\
\text { Gobierno } \\
\text { Federal. }\end{array}$ & $\begin{array}{l}\text { Objet } \\
\text { o de } \\
\text { crític } \\
\text { a por } \\
\text { exper } \\
\text { tos en } \\
\text { SP } \\
\text { Presi } \\
\text { dente } \\
\text { del } \\
\text { Sena } \\
\text { do y } \\
\text { minis } \\
\text { tros } \\
\text { de la } \\
\text { SCJN } \\
\text { critic } \\
\text { aron } \\
\text { al } \\
\text { Gobi } \\
\text { erno } \\
\text { feder } \\
\text { al por } \\
\text { no } \\
\text { aplica } \\
\text { r las } \\
\text { herra } \\
\text { mient } \\
\text { as } \\
\text { que } \\
\text { aprue } \\
\text { ba el } \\
\text { CU }\end{array}$ & $\begin{array}{l}\text { Presidente } \\
\text { Felipe } \\
\text { Calderón } \\
\text { admitió la } \\
\text { dificultad } \\
\text { para } \\
\text { rastrear } \\
\text { recursos de } \\
\text { procedenci } \\
\text { a ilícita e } \\
\text { instruyó al } \\
\text { secretario } \\
\text { de } \\
\text { Hacienda, } \\
\text { Ernesto } \\
\text { Cordero, y } \\
\text { al } \\
\text { gobernador } \\
\text { del Banco } \\
\text { de México, } \\
\text { Agustín } \\
\text { Carstens, a } \\
\text { buscar } \\
\text { nuevos } \\
\text { mecanismo } \\
\text { s que } \\
\text { ataquen } \\
\text { con mayor } \\
\text { eficacia } \\
\text { este ilícito. }\end{array}$ \\
\hline
\end{tabular}


Revista Jurídica del Departamento de Derecho

Academia de Derecho Administrativo

Tercera Época Año2. No. 5. Vol. 1/ Julio-Diciembre 2011.

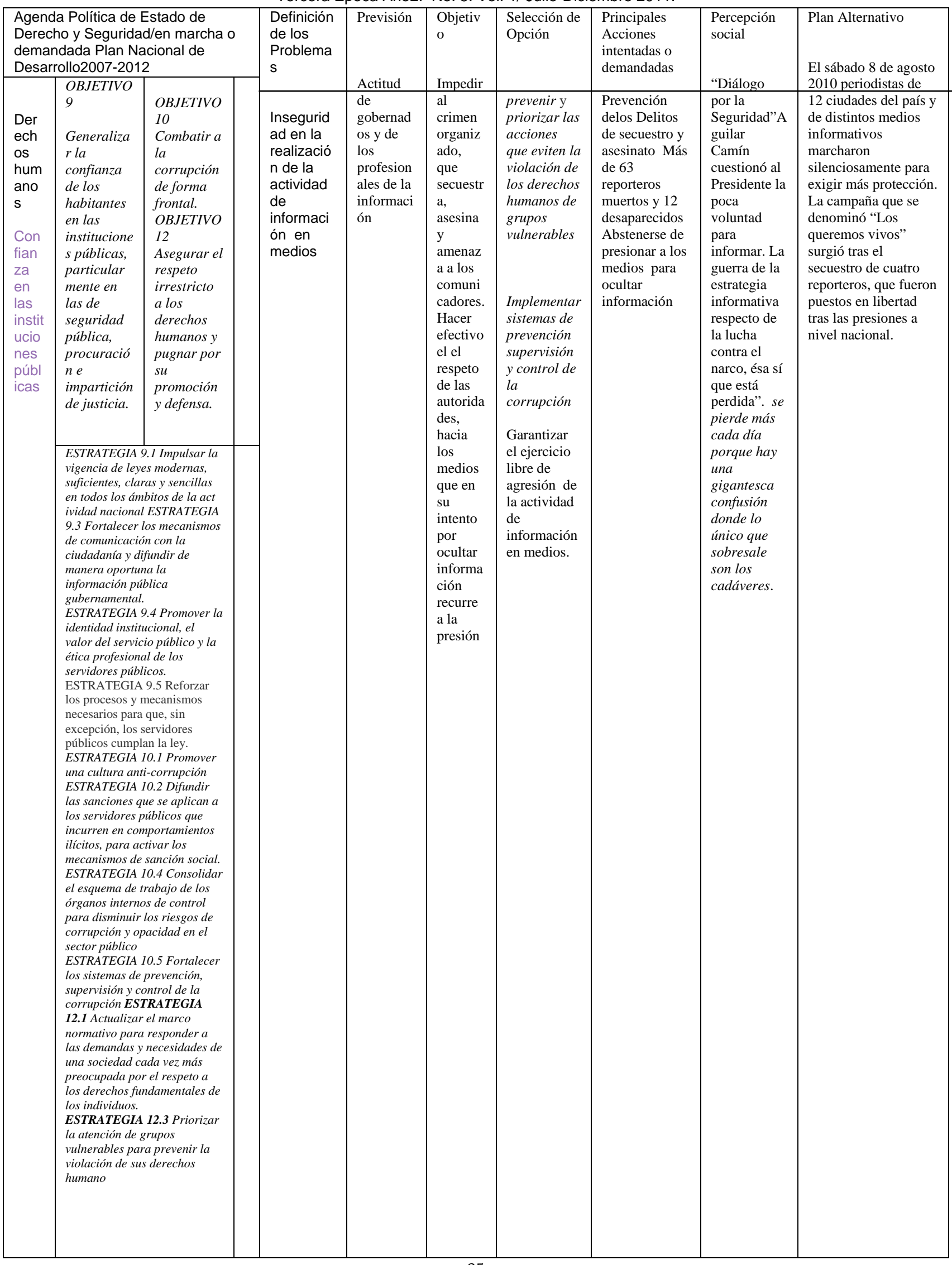


Revista Jurídica del Departamento de Derecho

Academia de Derecho Administrativo

Tercera Época Año2. No. 5. Vol. 1/ Julio-Diciembre 2011.

\begin{tabular}{|c|c|c|c|c|c|c|c|c|}
\hline \multicolumn{2}{|c|}{$\begin{array}{l}\text { Agenda Política de Estado de } \\
\text { Derecho y Seguridad/en marcha o } \\
\text { demandada Plan Nacional de } \\
\text { Desarrollo2007-2012 }\end{array}$} & \multirow[t]{2}{*}{$\begin{array}{l}\text { Definición } \\
\text { de los } \\
\text { Problema } \\
\text { s }\end{array}$} & \multirow[t]{2}{*}{ Previsión } & \multirow[t]{2}{*}{$\begin{array}{l}\text { Objetiv } \\
\text { o }\end{array}$} & \multirow[t]{2}{*}{$\begin{array}{l}\text { Selección de } \\
\text { Opción }\end{array}$} & \multirow[t]{2}{*}{$\begin{array}{l}\text { Principales } \\
\text { Acciones } \\
\text { intentadas o } \\
\text { demandadas }\end{array}$} & \multirow[t]{2}{*}{ Percepción social } & \multirow[t]{2}{*}{$\begin{array}{l}\text { Plan } \\
\text { Alternativo }\end{array}$} \\
\hline Inform & $\begin{array}{l}\text { OBJETIVO } 7 \\
\text { Establecer mecanismos y procesos }\end{array}$ & & & & & & & \\
\hline $\begin{array}{l}\text { ación } \\
\text { e } \\
\text { intelig } \\
\text { encia } \\
\text { Crime } \\
\text { n } \\
\text { organi } \\
\text { zado }\end{array}$ & $\begin{array}{l}\text { que permitan conocer } \\
\text { sistemáticamente las características } \\
\text { y patrones del fenómeno delictivo } \\
\text { en México, y aseguren la } \\
\text { disponibilidad de información } \\
\text { conffiable y oportuna. } \\
\text { OBJETIVO } 8 \\
\text { Recuperar la fortaleza del Estado y } \\
\text { la seguridad en la convivencia social } \\
\text { mediante el combate frontal y eficaz } \\
\text { al narcotráfico y otras expresiones } \\
\text { del crimen organizado. } \\
\text { ESTRATEGIA } 7.1 \text { Desarrollar e } \\
\text { implementar sistemas de } \\
\text { información y comunicaciones de } \\
\text { alta tecnología para el combate a la } \\
\text { delincuencia. } \\
\text { ESTRATEGIA } 7.2 \text { Generar, } \\
\text { fortalecer y coordinar los sistemas } \\
\text { de inteligencia en el Gobierno } \\
\text { Federal. } \\
\text { ESTRATEGIA } 8.1 \text { Aplicar la fuerza } \\
\text { del Estado, en el marco de la ley, } \\
\text { para recuperar los espacios que han } \\
\text { sido secuestrados por las bandas } \\
\text { de narcotraficantes y otras } \\
\text { organizaciones delictivas. }\end{array}$ & $\begin{array}{l}\text { Apropiaci } \\
\text { ón de } \\
\text { espacios } \\
\text { por las } \\
\text { bandas } \\
\text { de } \\
\text { narcotrafi } \\
\text { cantes y } \\
\text { otras } \\
\text { organizac } \\
\text { iones } \\
\text { delictivas. }\end{array}$ & $\begin{array}{l}\text { Actitud } \\
\text { de } \\
\text { sociedad } \\
\text { civil en } \\
\text { relación a } \\
\text { aceptar } \\
\text { que el } \\
\text { ejercito } \\
\text { sustituya } \\
\text { a la } \\
\text { policía } \\
\text { en las } \\
\text { ciudades } \\
\text { y en } \\
\text { relación a } \\
\text { la } \\
\text { propuesta } \\
\text { de } \\
\text { reformar } \\
\text { la Ley de } \\
\text { Segurida } \\
\text { d } \\
\text { Nacional } \\
\text { para } \\
\text { “blindar” } \\
\text { jurídicam } \\
\text { ente la } \\
\text { participac } \\
\text { ión } \\
\text { militar en } \\
\text { el } \\
\text { combate } \\
\text { a las } \\
\text { organizac } \\
\text { iones } \\
\text { criminale } \\
\text { s }\end{array}$ & $\begin{array}{l}\text { Recuper } \\
\text { ar } \\
\text { espacio } \\
\text { s } \\
\text { público } \\
\text { s y } \\
\text { privado } \\
\text { s } \\
\text { secuestr } \\
\text { ados } \\
\text { por el } \\
\text { crimen } \\
\text { organiz } \\
\text { ado }\end{array}$ & $\begin{array}{l}\text { Reformar la } \\
\text { Ley de } \\
\text { Seguridad } \\
\text { Nacional } \\
\text { para } \\
\text { "blindar" } \\
\text { jurídicament } \\
\text { e la } \\
\text { participació } \\
\text { n militar en } \\
\text { el combate a } \\
\text { las } \\
\text { organizacio } \\
\text { nes } \\
\text { criminales }\end{array}$ & $\begin{array}{l}\text { Desplegar en } \\
\text { distintos } \\
\text { estados al } \\
\text { Ejército para } \\
\text { que combata al } \\
\text { crimen } \\
\text { organizado } \\
\text { Primer Grupo } \\
\text { Michoacán, } \\
\text { Chihuahua B } \\
\text { California } \\
\text { Sinaloa } \\
\text { Nuevo León y } \\
\text { Tamaulipas } \\
\text { Segundo } \\
\text { Grupo } \\
\text { Veracruz }\end{array}$ & $\begin{array}{l}\text { Expertos } \\
\text { advirtieron que las } \\
\text { Fuerzas federales } \\
\text { no estaban } \\
\text { capacitadas para } \\
\text { patrullar en } \\
\text { ciudades, por lo } \\
\text { que temieron } \\
\text { abusos. } \\
\text { Las quejas en la } \\
\text { Comisión Nacional } \\
\text { de Derechos } \\
\text { Humanos (CNDH) } \\
\text { se dispararon al } \\
\text { grado de ser la } \\
\text { institución con más } \\
\text { recomendaciones }\end{array}$ & $\begin{array}{l}\text { Presidente } \\
\text { Felipe } \\
\text { Calderón } \\
\text { propone la } \\
\text { coordinación } \\
\text { voluntariamen } \\
\text { te a } \\
\text { fuerzasentre } \\
\text { los gobiernos } \\
\text { de las } \\
\text { entidades } \\
\text { federativas } \\
\text { afectadas } \\
\text { extraordinaria } \\
\text { mente para } \\
\text { permitir la } \\
\text { intervención } \\
\text { de las fuerzas } \\
\text { armadas } \\
\text { federales en su } \\
\text { territorio que } \\
\text { ataquen con } \\
\text { mayor eficacia } \\
\text { al crimen } \\
\text { organizado }\end{array}$ \\
\hline
\end{tabular}

De lo anterior tenemos que

A manera de Conclusiones

- No obstante que en el Plan Nacional de Desarrollo 2007-2012 se contemplan 5 Ejes de Políticas Públicas y entre éstas la de "Estado de Derecho y Seguridad,"( la cual se desagrega a su vez en varios rubros), tanto las autoridades y los gobernados proponen nuevas acciones o nuevos mecanismos que requieren para su implementación en algunos casos de :

a) respaldo dentro del orden jurídico para salvaguardar el estado de derecho (vbg.reformar la Ley de Seguridad Nacional a fin de justificar la intervención del ejército en funciones de policía ---desafortunadas.-vbg Nuevo León asesinato de 2 estudiantes de posgrado del ITESM, Baja California Caso Hank Rohn,-- y si bien no afortunadas vbg Veracruz al detener supuestamente a los ” responsables” de 32 y 36 Cadáveres).

b) En otros casos además un previo e intenso debate en distintos foros como el que hoy nos reúne como lo es el caso de la propuesta de legalización de las drogas; asimismo la de prevenir y priorizar las acciones que eviten la violación de los derechos humanos de grupos vulnerables(integrantes de medios de información) 
c) Garantizar el ejercicio libre y sin presiones gubernamentales o privadas de la actividad de información a través de la Implementación de sistemas de prevención,supervisión y control de la corrupción entre otras acciones y evitar con ello el estancamiento ${ }^{23}$

d) Por lo anterior se comprueba la hipótesis "el tema de las PP en materia de Seguridad Pública ha estado, está y desafortunadamente estará en permanente proceso de discusión, sin avances concretos en la consecución de los objetivos que se supone se deben alcanzar en el transcurso de la Política Pública, y en el tiempo fijado previamente.

e)Todo ello en tanto no se tome conciencia de que una política no debe elaborarse en forma reactiva y urgente sino con sentido propositivo, intencional, planeado y puesta en marcha para alcanzar los objetivos propuestos, con diversos medios y múltiples operadores.

e) Hasta el día de hoy el Ejército en la calle y la ley de extinción de dominio son las únicas acciones concretas contra la inseguridad y que en contrapartida en términos de costo beneficio las cifras que se arrojan son negativas 48,000 cadáveres, mas de 10,000 desaparecidos,230,000 desplazados,1300 jóvenes y niños asesinados, amén de la constante violación de los derechos de la población civil en particular de grupos vulnerables por género(mujeres), ocupación u oficio(periodistas, restauranteros, médicos, abogados litigantes, jueces, presidentes municipales, legisladores), desocupación (migrantes),minoría de edad (jóvenes,niños) quienes son victimizados por partida doble: por el crimen organizado y las propias autoridades. ¿es esta la seguridad que demanda el ciudadano mexicano y es ésta el tipo de seguridad que ofrecen los gobiernos federal, local y municipal en turno?

Referencias Bibliografícas y Webgrafía AguilarVillanueva Luis, Estudio Introductorio a las Políticas Públicas México.Ed.Miguel Angel Porrúa, 1992 Colección de antologías de políticas públicas

Buen día Alejandro,’Políticas públicas,enfoques y prospectivas”, Revista del Instituto de Administración Pública del Estado de Mëxico.(IAPEM),México,julio-agosto,1997 Jenkins, Williams,Policy Analisisa political and organization perspective, Inglaterra,Mortin Robertson and Company,1978 López Ruiz Domingo Cadenas Ayala Carlos Eduardo,¿Qué Es Una Política Pública?

http://www.diputados.gob.mx http://pnd.calderon.presidencia.gob.mx/eje1/derechos-humanos.htm www.unla.edu.mx

\footnotetext{
${ }^{23}$ como se dio en relación a la propuesta Calderonista de conformar una Policía Nacional Única que luego de más de tres años de gestión, solo se ha avanzado en estado de extrema urgencia como Veracruz y Oaxaca en una "coordinación voluntaria EstadosFederación para que intervengan las fuerzas armadas en funciones de policía”, pues además del cambio de discurso, del Presidente de conformar 32 policías estatales los alcaldes y gobernadores no se ponen de acuerdo. La iniciativa sigue en el aire.
} 